\title{
Titanium peroxide nanoparticles enhanced cytotoxic effects of $X$-ray irradiation against pancreatic cancer model through reactive oxygen species generation in vitro and in vivo
}

Masao Nakayama ${ }^{1}$, Ryohei Sasaki ${ }^{1 *}$, Chiaki Ogino ${ }^{2}$, Tsutomu Tanaka $^{2}$, Kenta Morita ${ }^{2}$, Mitsuo Umetsu ${ }^{3}$, Satoshi Ohara ${ }^{4}$, Zhenquan Tan ${ }^{4}$, Yuya Nishimura², Hiroaki Akasaka' ${ }^{1}$ Kazuyoshi Sato ${ }^{5}$, Chiya Numako ${ }^{6}$, Seiichi Takami ${ }^{7}$ and Akihiko Kondo ${ }^{2}$

\begin{abstract}
Background: Biological applications of nanoparticles are rapidly increasing, which introduces new possibilities to improve the efficacy of radiotherapy. Here, we synthesized titanium peroxide nanoparticles (TiOxNPs) and investigated their efficacy as novel agents that can potently enhance the effects of radiation in the treatment of pancreatic cancer.

Methods: TiOxNPs and polyacrylic acid-modified TiOxNPs (PAA-TiOxNPs) were synthesized from anatase-type titanium dioxide nanoparticles $\left(\mathrm{TiO}_{2} \mathrm{NPs}\right.$ ). The size and morphology of the PAA-TiOxNPs was evaluated using transmission electron microscopy and dynamic light scattering. The crystalline structures of the $\mathrm{TiO}_{2} \mathrm{NPs}$ and PAA-TiOxNPs with and without X-ray irradiation were analyzed using X-ray absorption. The ability of TiOxNPs and PAA-TiOxNPs to produce reactive oxygen species in response to $X$-ray irradiation was evaluated in a cell-free system and confirmed by flow cytometric analysis in vitro. DNA damage after $X$-ray exposure with or without PAA-TiOxNPs was assessed by immunohistochemical analysis of $\mathrm{Y}-\mathrm{H} 2 \mathrm{AX}$ foci formation in vitro and in vivo. Cytotoxicity was evaluated by a colony forming assay in vitro. Xenografts were prepared using human pancreatic cancer MIAPaCa-2 cells and used to evaluate the inhibition of tumor growth caused by X-ray exposure, PAA-TiOxNPS, and the combination of the two.

Results: The core structures of the PAA-TiOxNPs were found to be of the anatase type. The TiOxNPs and PAA-TiOXNPs showed a distinct ability to produce hydroxyl radicals in response to $X$-ray irradiation in a dose- and concentration-dependent manner, whereas the $\mathrm{TiO}_{2} \mathrm{NPs}$ did not. At the highest concentration of TiOxNPs, the amount of hydroxyl radicals increased by $>8.5$-fold following treatment with 30 Gy of radiation. The absorption of PAA-TiOxNPs enhanced DNA damage and resulted in higher cytotoxicity in response to $X$-ray irradiation in vitro. The combination of the PAA-TiOxNPs and X-ray irradiation induced significantly stronger tumor growth inhibition compared to treatment with either PAA-TiOxNPs or X-ray alone $(p<0.05)$. No apparent toxicity or weight loss was observed for 43 days after irradiation.
\end{abstract}

Conclusions: TiOxNPs are potential agents for enhancing the effects of radiation on pancreatic cancer and act via hydroxyl radical production; owing to this ability, they can be used for pancreatic cancer therapy in the future.

Keywords: Nanoparticle, Titanium peroxide, Radiation, Reactive oxygen species, Pancreatic cancer

\footnotetext{
* Correspondence: rsasaki@med.kobe-u.ac.jp

'Division of Radiation Oncology, Kobe University Graduate School of

Medicine, 7-5-2 Kusunokicho, Chuouku, Kobe, Hyogo 650-0017, Japan

Full list of author information is available at the end of the article
} 


\section{Background}

Pancreatic cancer is a highly lethal disease that is often diagnosed only in the advanced stage. It is the fourth most common cause of cancer-related deaths in the United States, causing 40,560 deaths annually [1]. Moreover, the 5-year survival rate of pancreatic cancer patients is approximately 3-7 \% after diagnosis $[1,2]$. Locally advanced pancreatic cancer is also notoriously resistant to many types of cytotoxic chemotherapy and radiotherapy [3]. As a result, there are currently no effective therapies for pancreatic cancer, and novel strategies need to be explored.

The biological application of nanoparticles (NPs) is rapidly increasing in nanotechnology and introduces new possibilities for the diagnosis and treatment of human cancers [4-6]. NPs have been used in many different areas of radiation oncology, including radiosensitization [7]. Nano-sized titanium dioxide $\left(\mathrm{TiO}_{2}\right)$ is one of the most widely produced nanoparticles. $\mathrm{TiO}_{2}$ is poorly soluble and has been used in numerous applications as a food colorant, or as a white pigment in a number of products including cosmetics, medicines, and pharmaceutical products $[8,9]$. Rutile and anatase are the two major crystalline forms of $\mathrm{TiO}_{2}$. The photocatalytic activity and cytotoxicity of anatase $\mathrm{TiO}_{2}$ nanoparticles $\left(\mathrm{TiO}_{2} \mathrm{NPs}\right)$ are higher than those of the rutile forms $[10,11]$. Recently, $\mathrm{TiO}_{2} \mathrm{NPs}$ have been used in the phototherapy of malignant cells and are regarded as potential photosensitizing agents for photodynamic therapy because they exert unique phototoxic effects upon ultraviolet (UV) irradiation [12-16]. Despite the promising effects of $\mathrm{UV}$-activated $\mathrm{TiO}_{2} \mathrm{NPs}$, this strategy seems to be ineffective in treating many cancers and is difficult to apply clinically for two major reasons. First, UV light cannot penetrate the human body to reach internal organs such as the gastrointestinal system, liver, and pancreas, thus limiting the application of this technique to superficial tumors [17]. Second, the UV-mediated production of reactive oxygen species (ROS) occurs for a very short duration and is insufficient to provide a continuous and prolonged cancer-killing effect [18]. Radiotherapy using X-rays is known to be effective in various cancer treatments. However, to our knowledge, there are few reports investigating whether or not $\mathrm{TiO}_{2} \mathrm{NPs}$ can enhance the effects of X-ray irradiation [19]. In addition, the properties of $\mathrm{TiO}_{2} \mathrm{NPs}$ seem to be insufficient to render them useful as radiosensitizers. Wang et al. demonstrated that the potential biological effects of $\mathrm{TiO}_{2} \mathrm{NPs}$ depend on their size, crystal phase, surface coating, and chemical composition [20]. Therefore, certain modifications may be necessary to make $\mathrm{TiO}_{2} \mathrm{NPs}$ suitable for use as agents that enhance the effects of radiation.

Chemical reactions between hydrogen peroxide and $\mathrm{TiO}_{2}$ have been widely investigated [21, 22], but the effects of these reactions on the properties of $\mathrm{TiO}_{2} \mathrm{NPs}$ in response to X-ray irradiation have not been clarified. In this study, we investigated the properties of titanium peroxide nanoparticles ( $\mathrm{TiOxNPs}$ ) to determine whether the TiOxNPs might be useful as potential agents to enhance the effects of radiation against a human pancreatic cancer model in vitro and in vivo.

\section{Materials and methods \\ Preparation of TiOxNPs}

TiOxNPs were synthesized from anatase-type $\mathrm{TiO}_{2} \mathrm{NPs}$ according to several procedures that involve hydrogen peroxide processing (Fig. 1a) [23]. For in vitro and in vivo experiments, the surfaces were modified using polyacrylic acid (PAA) to prevent aggregation of the bare TiOxNPs under physiological conditions [24]. The material for the $\mathrm{TiO}_{2} \mathrm{NPs}$ (STS-01) was purchased from Ishihara Sangyo, Ltd. (Osaka, Japan). Details of the syntheses of TiOxNPs and PAA-TiOxNPs are shown in Additional file 1.

\section{Transmission electron micrography (TEM), dynamic light scattering (DLS), and X-ray absorption fine structure (XAFS) analyses}

The size and morphology of the PAA-TiOxNPs were studied using a transmission electron microscope (JEM1200EX, JEOL Ltd., Tokyo, Japan) as described previously [25]. The transmission electron micrographs were recorded at an acceleration voltage of $80 \mathrm{kV}$. DLS was conducted using a Malvern Zetasizer Nano ZS to estimate the hydrodynamic diameter of the PAA-TiOxNPs.

The XAFS measurements in fluorescence mode were performed around a Ti K-edge energy region at BL9A at the Photon Factory, KEK, Japan. Synchrotron radiation from a $2.5 \mathrm{GeV}$ storage ring was monochromatized using a Si (111) double crystal monochromator modified to $2 \times 1 \mathrm{~mm}^{2}$ with slits and counted using an ion chamber for I0 and a Lytle-type detector for fluorescence X-rays. Higher harmonic radiation was removed using an $\mathrm{Rh}-\mathrm{Ni}$ coated mirror. The $\mathrm{TiO}_{2} \mathrm{NP}$ and PAA-TiOxNP suspensions were put into polyethylene bags for the XAFS measurements. $\mathrm{TiO}_{2}$ minerals (rutile and anatase) on Scotch tape were measured as standard titanium materials with known chemical compositions and crystal structures.

\section{Cell culture and establishment of the animal models}

The MIAPaCa-2 human pancreatic cancer cell line was obtained from the American Type Culture Collection (Rockville, MD, USA) and maintained in RPMI-1640 medium. Male BALB/c nude mice (body weight: 20-22 g) were purchased from CLEA Corporation (Tokyo, Japan). The nude mice were maintained in specific pathogenfree animal care facilities under isothermal conditions with regular photoperiods. All animal experiments were approved by the Institutional Animal Care and Use Committee (Permission number: 100605R1) and performed 


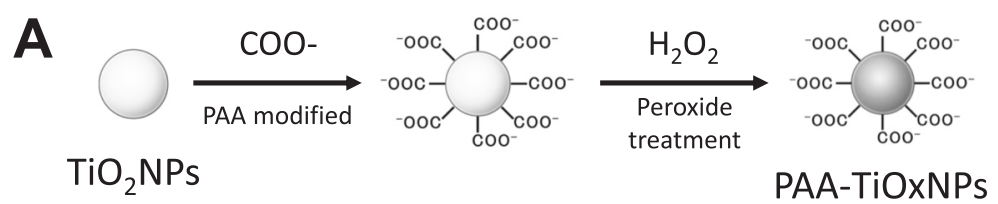

B

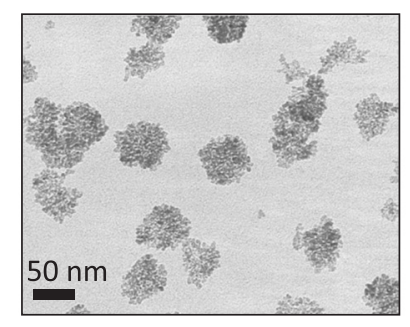

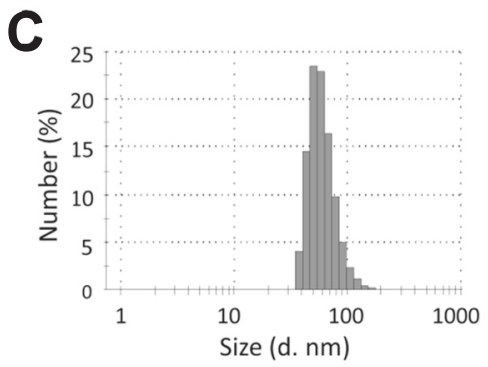

D

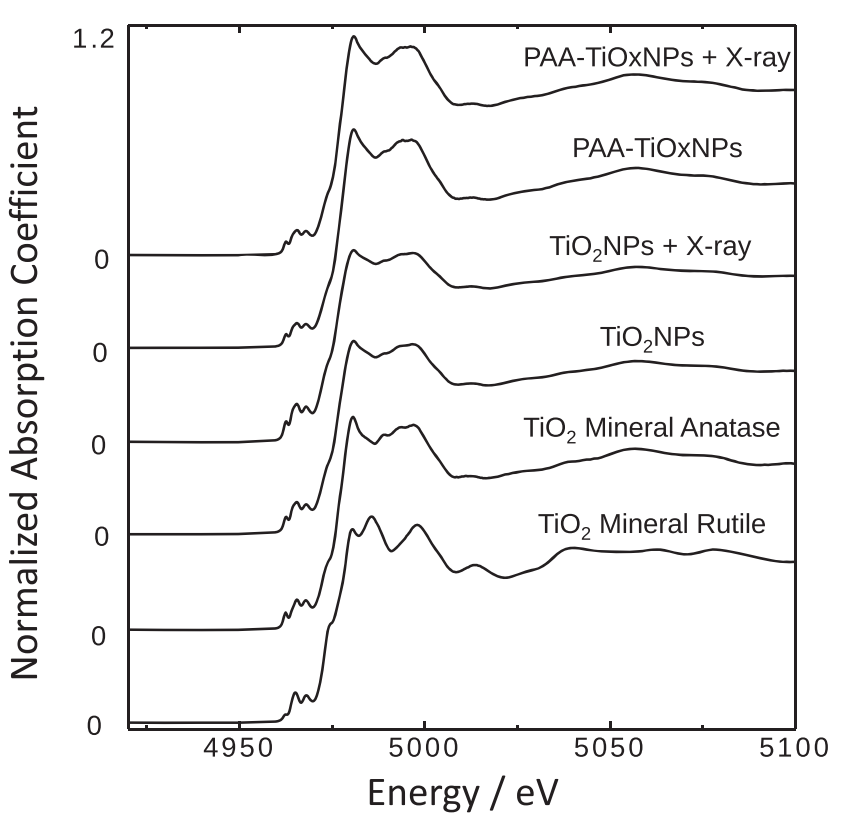

Fig. 1 Characteristics of the PAA-TiOxNPs. a Scheme for the synthesis of the PAA-TiOxNPs from anatase $\mathrm{TiO}_{2} \mathrm{NPs}$. $\mathbf{b}$ Representative TEM image of the PAA-TiOxNPs. The size of the PAA-TiOxNPs was approximately $50 \mathrm{~nm}$. c Size distribution of the PAA-TiOxNPs measured by DLS. $\mathbf{d}$ Structure of $\mathrm{TiO}_{2} \mathrm{NPS}$ and PAA-TiOxNPs before and after X-ray irradiation, as determined by XAFS spectra

according to Kobe University Animal Experimentation Regulations.

\section{X-ray irradiation}

X-ray irradiation was performed using a MBR-1505R2 (Hitachi, Tokyo, Japan) at a voltage of $150 \mathrm{kV}$ and a current of $5 \mathrm{~mA}$ with a 1-mm-thick aluminum filter (0.5 Gy/min at the target). Prior to each experiment, the mice were anesthetized using an intraperitoneal administration of somnopentyl $(0.1 \mathrm{mg} / \mathrm{g}$ body weight) and were then put to sleep under anesthesia and immobilized in a customized harness that exposed the hind leg while shielding the remainder of the body with lead during irradiation.

\section{ROS evaluation}

Quantification of ROS generation from the NPs in response to X-ray irradiation in a cell-free system was performed using 3'-(p-aminophenyl) fluorescein (APF; Sekisui Medical Co. Ltd., Tokyo, Japan), which fluoresces mainly in response to hydroxyl radicals [26]. APF $(5 \mu \mathrm{M})$ was added to different concentrations of the suspensions of TiOxNPs, PAA-TiOxNPs, and $\mathrm{TiO}_{2} \mathrm{NPs}_{\text {s }}$ prepared using 96-well plates. Each plate was then exposed to different doses of X-ray radiation. The APF signal was measured using a multi-well plate reader (Fluoroskan Ascent FL, Thermo Fisher Scientific Inc., MA, USA) at excitation/ emission wavelengths of $490 / 515 \mathrm{~nm}$. To determine whether the increase in APF fluorescent signals was 
caused by ROS generation, antioxidants such as vitamin $\mathrm{C}$ (1 $\mathrm{mM})$ or glutathione $(1 \mathrm{mM})$ were added as ROS scavengers. The amount of hydrogen peroxide was measured in response to carboxy-2', 7'-dichlorofluorescein $\left(\mathrm{C}-\mathrm{H}_{2} \mathrm{DCF}\right.$; Molecular Probes, Inc., Eugene, OR, USA). $\mathrm{C}-\mathrm{H}_{2} \mathrm{DCF}(50 \mu \mathrm{M})$ was added to suspensions of TiOxNPs, which were then exposed to X-ray radiation. The fluorescent signal was measured at excitation/ emission wavelengths of 485/612 nm.

The production of intracellular ROS including hydrogen peroxide, hydroxyl radicals, and superoxide anions was evaluated using a fluorescence activated cell sorting (FACS Calibur; Becton-Dickinson, NJ, USA). The MIAPaCa-2 cells were treated with $0.1 \% \mathrm{w} / \mathrm{v}$ PAA-TiOxNPs for $1 \mathrm{~h}$ at $37{ }^{\circ} \mathrm{C}$ with or without $30 \mathrm{~Gy} \mathrm{X}$-ray irradiation. For $30 \mathrm{~min}$, the cells were stained with $10 \mu \mathrm{M}$ APF, $50 \mu \mathrm{M} \mathrm{C}-\mathrm{H}_{2} \mathrm{DCF}$, and $50 \mathrm{ng} / \mathrm{mL}$ hydroethidium (HE; Molecular Probes, Inc., OR, USA) per sample to detect cellular hydroxyl radicals, hydrogen peroxide, and superoxide anions, respectively [27].

\section{Detection of DNA damage and colony forming assay in vitro}

Induction of deoxyribonucleic acid (DNA) damage was investigated by the detection of phosphorylated histone 2AX ( $\gamma-\mathrm{H} 2 \mathrm{AX})$ foci using immunocytochemistry. MIAPaCa- 2 cells were subcultured on $35-\mathrm{mm}$ dishes. The cells were treated with $0.15 \%$ w/v PAA-TiOxNPs for $1 \mathrm{~h}$ and/or 5 Gy of X-ray irradiation. After the treatment, the cells were fixed in $4 \%$ paraformaldehyde in phosphate buffered saline (PBS) for $20 \mathrm{~min}$, permeabilized with $0.1 \%$ Triton X-100 in PBS for $5 \mathrm{~min}$, and blocked in $5 \%$ bovine serum albumin in PBS for $60 \mathrm{~min}$. Cells were incubated with 1:200 rabbit anti $\gamma-\mathrm{H} 2 \mathrm{AX}$ antibody (Cell Signaling Technology, MA, US) overnight at $4{ }^{\circ} \mathrm{C}$. Then, the cells were incubated with 1:20 tetramethyl rhodamine isothiocyanate (TRITC)-conjugated anti-rabbit secondary antibody (Dako, Glostrup, Denmark) for $90 \mathrm{~min}$ at room temperature. Cell nuclei were stained with 4, 6-diaidino-2phenylindole (DAPI). Stained cells were observed using a fluorescence microscope (BZ-9000, KEYENCE, Osaka, Japan). Cells expressing nuclear $\gamma-\mathrm{H} 2 \mathrm{AX}$ foci were then counted manually from 100 cells for each treatment, and the data were presented as the mean \pm standard deviation (SD) from 3 fields for each section [28].

To evaluate whether the PAA-TiOxNPs might enhance the effects of radiation in vitro, a colony forming assay was performed. MIAPaCa- 2 cells $\left(1 \times 10^{6}\right)$ were exposed to $0.15 \% \mathrm{w} / \mathrm{v}$ PAA-TiOxNPs for $30 \mathrm{~min}$, and then they were treated with 0,3 , or 5 Gy of X-ray irradiation. The treated cells were counted and replated onto a new $10-\mathrm{cm}$ tissue culture dish with fresh medium not containing PAA-TiOxNPs. The cells were incubated for 10 days until the cell population completed colony formation. After fixing and staining, colonies consisting of more than 50 cells were counted and the surviving fractions were calculated based on the survival of nonirradiated cells.

\section{Tumor growth inhibition of PAA-TiOxNPs combined with $\mathrm{X}$-ray radiation}

MIAPaCa- 2 cells $\left(2 \times 10^{6}\right)$ were injected subcutaneously into the hind legs of the BALB/c nude mice as described previously [29]. The tumor was expected to enlarge to be palpable, i.e., approximately $6-10 \mathrm{~mm}$ in the longest axis and $5-7 \mathrm{~mm}$ in the shortest axis, with skin thickness by 7 days post injection. Tumor volume was calculated using the formula $\mathrm{L} \times \mathrm{W}^{2} / 2$, where $\mathrm{L}$ is the longest axis and $\mathrm{W}$ is the shortest axis of the tumor. Using this formula, the tumor volume was approximately 100$200 \mathrm{~mm}^{3}$ on the treatment day. The mice were stratified into 4 subgroups consisting of 3 mice each: untreated, PAA-TiOxNPs alone, $\mathrm{X}$-rays alone, and X-rays combined with PAA-TiOxNPs. The mice were given an intratumoral injection of $150 \mu \mathrm{L}$ of an $8.7 \%$ w/v PAATiOxNP suspension with or without a single dose of 5 Gy of X-ray irradiation approximately $1 \mathrm{~h}$ after the injection. To inject a sufficient amount of the PAATiOxNP suspension while keeping the suspension as homogeneous as possible, we injected $150 \mu \mathrm{L}$ of the PAA-TiOxNP suspension into each tumor. The tumor size, body weight, and health of the mice were measured for 43 days after the initial treatment (for a total of 50 days after the injection) [30].

\section{Mechanism of tumor growth inhibitory effect by PAA- TiOxNPs combined with X-ray irradiation}

At $24 \mathrm{~h}$ after treatment, the tumors were excised, fixed in $10 \%$ formalin, and embedded in paraffin sections (4- $\mu \mathrm{m}$-thick). The samples were stained using hematoxylin and eosin (H-E).

Induction and maintenance of DNA damage in the tumor by X-ray radiation with or without PAA-TiOxNPs was evaluated by detection of $\gamma-\mathrm{H} 2 \mathrm{AX}$ immunoreactivity using a fluorescence microscope (BZ-9000, Keyence, Osaka, Japan). Sections were counterstained with DAPI. Positive $\gamma$-H2AX signals in the nucleus were visually counted in 300 cells for each treatment. The number of $\gamma-\mathrm{H} 2 \mathrm{AX}$ foci was calculated by averaging the number of the positive cells from 3 fields for each section. Induction of apoptosis was also evaluated using the terminal deoxynucleotidyl transferase-mediated deoxyuridine triphosphate nick end labeling (TUNEL) assay (Roche Applied Science, Indianapolis, IN, US) [31]. Positive TUNEL signals were evaluated in 100 cells for each treatment, and the number of apoptotic cells was calculated by averaging the number of positive TUNEL signals from 6 fields for each section. 


\section{Statistical analysis}

Data are expressed as the mean $\pm \mathrm{SD}$. Comparisons were performed using Student's $t$-test, and differences were considered significant at the $95 \%$ confidence level $(p<0.05)$.

\section{Results}

\section{Successful preparation of TiOxNPs}

Considering the enhanced permeability and retention effect, we aimed to prepare nanoparticles with a size of less than $100 \mathrm{~nm}$. The PAA-TiOxNPs were found to be approximately $50-70 \mathrm{~nm}$ in diameter, as determined using TEM (Fig. 1b). Consistent with the TEM images, the size of the PAA-TiOxNPs, as determined using DLS, was approximately $50-100 \mathrm{~nm}$ with a narrow unimodal size distribution (Fig. 1c).

The crystalline structures of $\mathrm{TiO}_{2} \mathrm{NPs}$ and PAATiOxNPs with or without X-ray radiation (16 Gy) were analyzed using XAFS (Fig. 1d). No change in the coordination environment was observed around the $\mathrm{Ti}$ ion from the original anatase-type $\mathrm{TiO}_{2} \mathrm{NPs}$ until the PAA-TiOxNPs were irradiated with X-rays. From this observation, it was concluded that the PAATiOxNPs preserve the anatase structure of $\mathrm{TiO}_{2} \mathrm{NPs}$ in the core structures.

\section{ROS-generating effect of TiOxNPs under X-ray irradiation}

The amount of hydroxyl radicals increased in a radiation dose- and nanoparticle concentration-dependent manner in the TiOxNPs and PAA-TiOxNPs, whereas no increase in hydroxyl radical levels was observed in the $\mathrm{TiO}_{2} \mathrm{NPs}$ (Fig. 2a). At the highest concentration of TiOxNPs and PAA-TiOxNPs, the amount of hydroxyl radicals with $30 \mathrm{~Gy}$ of radiation increased by more than 8.5 and 3.7 fold, respectively. The ROS-generating effect using bare TiOxNPs appeared to be stronger than that of PAA-TiOxNPs. ROS production was also confirmed using antioxidants such as vitamin $\mathrm{C}$ and glutathione. When these antioxidants were added to the TiOxNP suspension, the APF signal did not increase, even with a radiation dose of 30 Gy (Fig. 2b). Thus, the TiOxNPs could produce large amounts of hydroxyl radicals under $\mathrm{X}$-ray irradiation. On the contrary, hydrogen peroxide production from the TiOxNPs did not increase under $\mathrm{X}$-ray irradiation (Fig. 2c).

To assess intracellular ROS production by PAATiOxNPs with X-ray radiation, the amount of hydroxyl radicals, hydrogen peroxide, and superoxide anions was measured using FACS. In cells treated with PAATiOxNPs combined with X-ray radiation, the hydroxyl radical levels increased by more than 2 fold and the hydrogen peroxide levels increased by more than 1.6 fold in comparison to the control, whereas the superoxide levels did not increase (Fig. 2d).
Cytotoxic effects of PAA-TiOxNPs under X-ray irradiation in vitro

First, intracellular absorption of PAA-TiOxNPs in MIAPaCa-2 cells was directly confirmed by TEM (Fig. 3a). Next, DNA damage induced by X-ray irradiation with or without PAA-TiOxNPs was quantified with regard to $\gamma-\mathrm{H} 2 \mathrm{AX}$ foci formation. Compared to $\mathrm{X}$-ray irradiation alone, combination with PAA-TiOxNPs induced a higher proportion of $\gamma-\mathrm{H} 2 \mathrm{AX}$ foci $(p<0.05$, Fig. 3b, c). The effect of the combination of PAATiOxNPs and X-ray irradiation evaluated by a colony forming assay was significantly better than that of Xrays alone $(p<0.05$, Fig. $3 \mathrm{~d})$. Overall, the PAATiOxNPs enhanced the cytotoxic effect of X-ray irradiation in vitro.

\section{Tumor growth inhibitory effects of PAA-TiOxNPs combined with $\mathrm{X}$-ray irradiation in vivo}

The tumor growth inhibition in the group receiving both the PAA-TiOxNPs and X-ray treatments was significantly greater than that in the groups that received a single treatment or in the untreated subgroups at 43 days after the initial treatment $(p<0.05$, Fig. $4 \mathrm{a}, \mathrm{b})$. The tumor volume in the mice treated with PAATiOxNPs and X-rays was $35.4 \%$ of that in mice treated with X-rays alone. Thus, the PAA-TiOxNPs in combination with $\mathrm{X}$-ray radiation had synergistic cytotoxic effects in vivo.

No immediate toxic reaction was observed in the mice injected with the PAA-TiOxNPs. No mice died during the 43-day observation period and none showed any apparent loss of body weight (Fig. 4c). These findings suggest that the PAA-TiOxNPs themselves do not have any apparent toxicity at the effective dose applied during this period.

\section{Mechanisms underlying tumor growth inhibitory effects in vivo}

The localization of the injected PAA-TiOxNPs was evaluated histologically. In H-E stained sections, PAA-TiOxNPs were observed as brown dots (Fig. 5a). The brown dots indicating aggregated PAA-TiOxNPs were observed inside the tumor cells. Immunoreactivity of $\gamma-\mathrm{H} 2 \mathrm{AX}$ indicating occurrence and maintenance of DNA damage in the tumor specimen was evaluated. The PAA-TiOxNPs combined with X-ray irradiation induced significantly higher numbers of positive cells compared to PAA-TiOxNPs or $\mathrm{X}$-ray irradiation alone $(p<0.05$, Fig. $5 \mathrm{~b}, \mathrm{c})$. The number of TUNEL-positive cells was also significantly higher in the combination group than in the single treatment or untreated subgroups $(p<0.05$, Fig. $5 \mathrm{~d}$, e). These findings indicate that the PAA-TiOxNPs enhanced the cytotoxicity of $\mathrm{X}$-ray radiation through DNA damage and induction of apoptosis. 

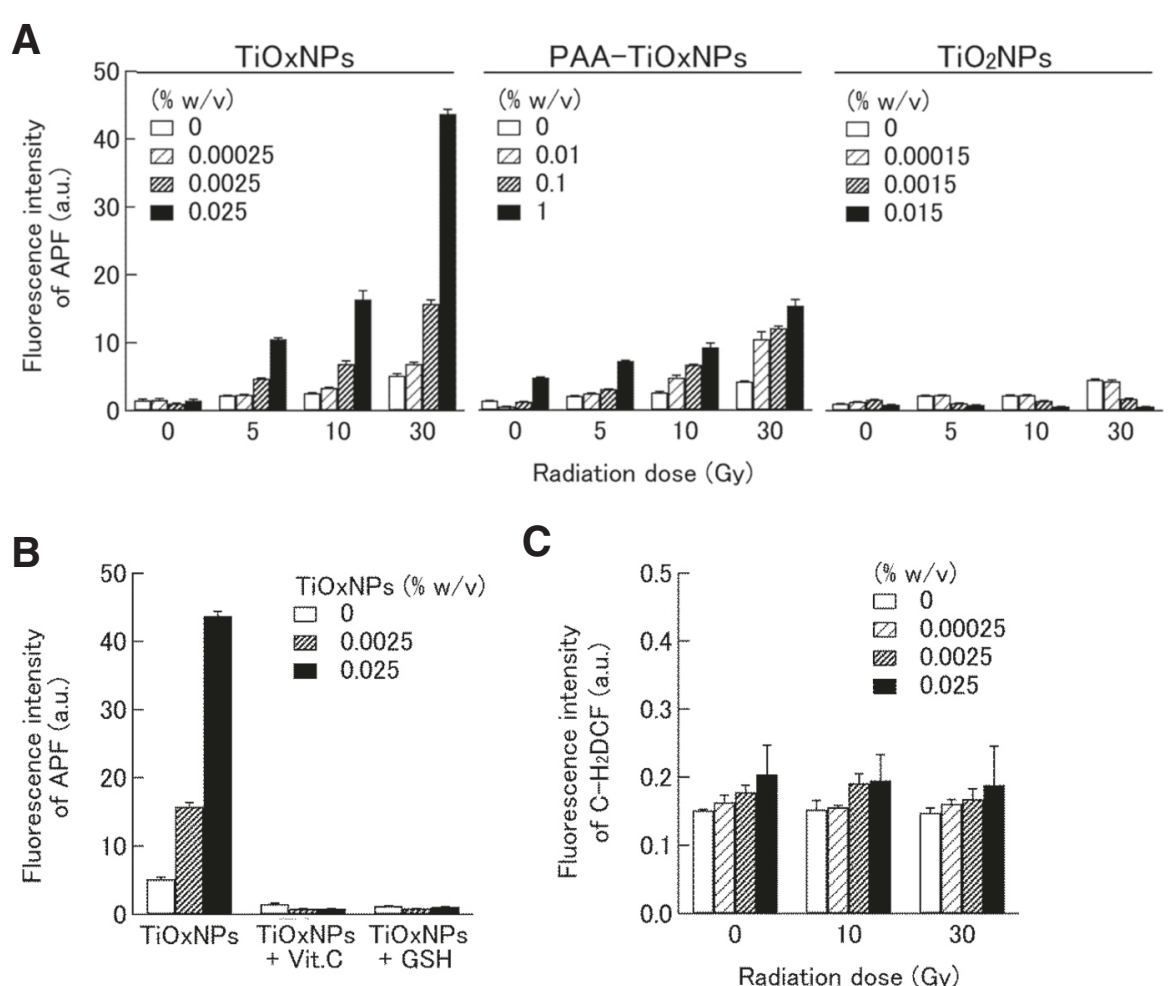

C
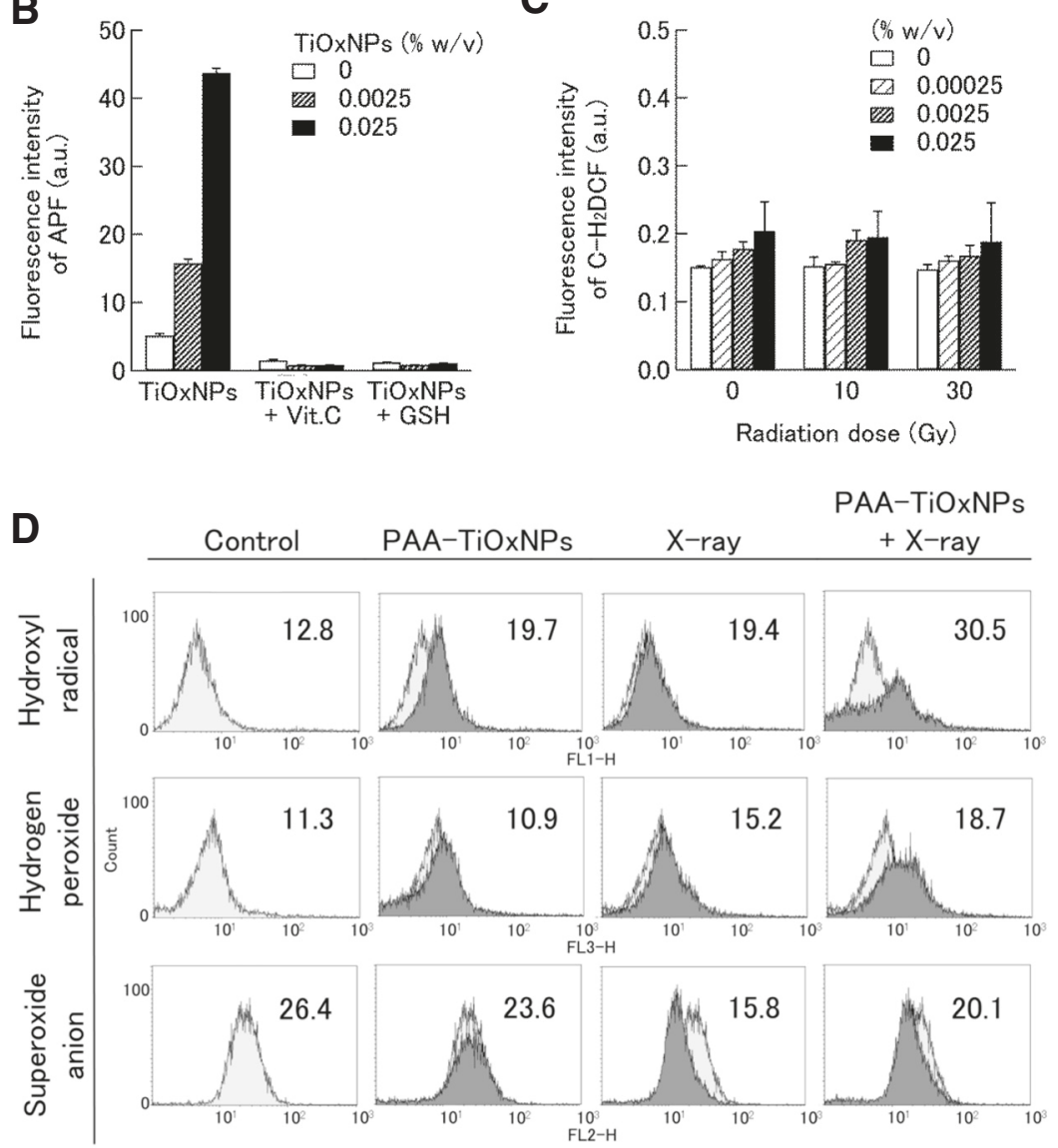

Fig. 2 ROS production by the TiOxNPS, PAA-TiOxNPS, and $\mathrm{TiO}_{2} \mathrm{NPS}$ under X-ray irradiation. a APF intensity indicating that hydroxyl radical production in the TiOxNPs and the PAA-TiOxNPs increased in a radiation dose-dependent manner, but that of the $\mathrm{TiO}_{2} \mathrm{NPs}_{\mathrm{s}}$ did not. Irradiated radiation doses were $0,5,10$, and $30 \mathrm{~Gy}$. Data are shown as the mean \pm SD from 5 independent experiments. b Production and scavenging of ROS by $1 \mathrm{mM}$ vitamin $\mathrm{C}$ (Vit. C) or $1 \mathrm{mM}$ glutathione (GSH). Histograms show mean \pm SD calculated from 5 independent experiments. c Hydrogen peroxide production from the TiOXNPs under X-ray irradiation. $\mathbf{d}$ Detection of intracellular ROS production by FACS. Mean fluorescence values are shown in each figure

\section{Discussion}

To our knowledge, this is the first report to show that TiOxNPs synthesized from anatase-type $\mathrm{TiO}_{2} \mathrm{NPs}$ can produce hydroxyl radicals under X-ray irradiation. This property resulted in remarkable tumor growth inhibition in a human pancreatic carcinoma xenograft.
The core of the PAA-TiOxNPs remained the same as that of $\mathrm{TiO}_{2} \mathrm{NPs}$ with the original anatase structure (Fig. 1d), whereas the property of the TiOxNPs to produce ROS in response to X-ray irradiation was different from that of $\mathrm{TiO}_{2} \mathrm{NPs}$ (Fig. 2a). Based on these findings and according to the process used to synthesize the 
A
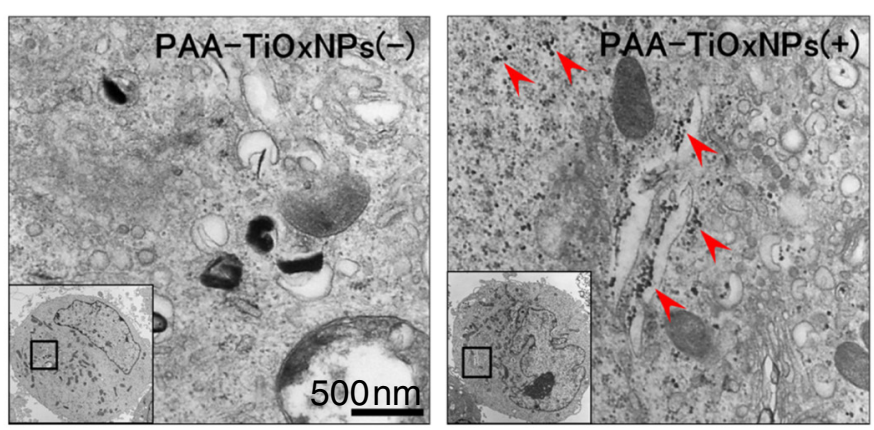

B
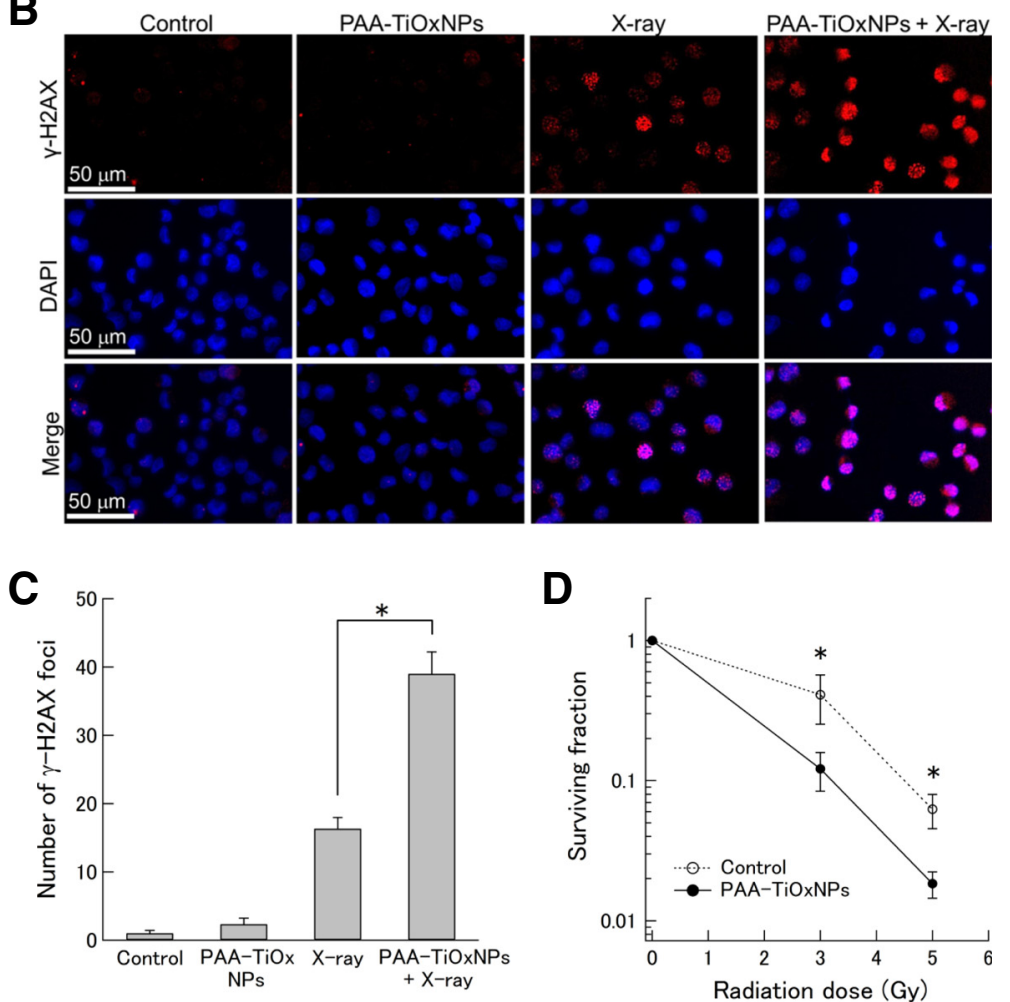

Fig. 3 PAA-TiOXNPs enhanced the effects of radiation in vitro. a TEM images showing PAA-TiOxNPs within the MIAPaCa-2 cells (red arrows). b, c DNA damage illustrated by immunohistochemistry of $\mathrm{Y}$-H2AX foci in the nucleus. The X-ray irradiation combined with PAA-TiOxNPs induced a higher proportion of $y-H 2 A X$ foci-positive cells compared to the single treatment of X-ray irradiation or PAA-TiOxNPs. Data are shown as the mean \pm SD. ${ }^{*} p<0.05$. d Significantly higher combination effects of X-ray irradiation with PAA-TiOxNPs were observed in a colony forming assay. Data are shown as the mean \pm SD from 3 independent experiments. ${ }^{*} p<0.05$

TiOxNPs, it was speculated that surface of the TiOxNPs was different from that of $\mathrm{TiO}_{2} \mathrm{NPs}$, and it seemed to be peroxidized by hydrogen peroxide. The acquired property of the TiOxNPs was first examined under cell-free conditions (only water and TiOxNPs) using APF. Because the APF reaction is specific to hydroxyl radicals, peroxynitrite anion, and hypochlorite anion [26], the major ROS generated from the TiOxNPs and PAA-TiOxNPs in response to $\mathrm{X}$-ray irradiation was identified as hydroxyl radicals. Next, this finding was further investigated in cells using FACS (Fig. 2d). The results indicated that the hydroxyl radical and hydrogen peroxide levels increased, whereas the levels of superoxide anions did not. These results were consistent with those observed in the cell-free system. Cellular redox homeostasis is maintained by the balance between the generation and elimination of ROS. Exogenous agents that increase ROS generation or decrease antioxidant capacity will shift the redox balance and result in an overall increase in the ROS levels, which may induce cell death when above a cellular tolerability threshold [32]. Cancer cells would be more dependent on the antioxidant system and more vulnerable to further oxidative stress induced by 


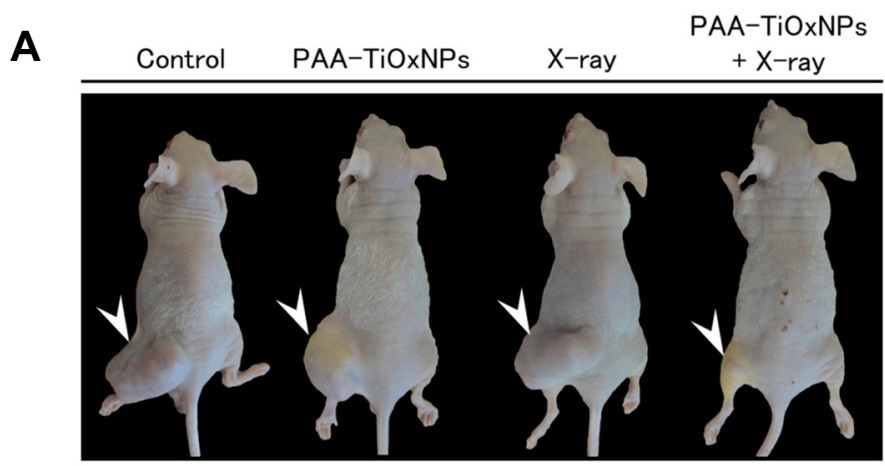

B

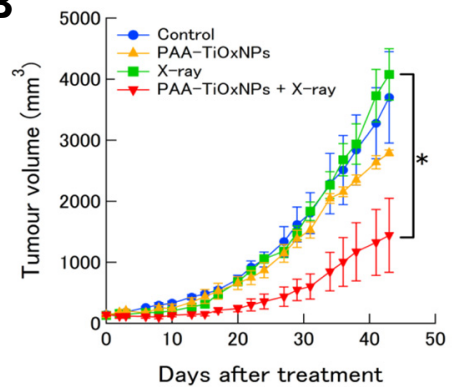

C

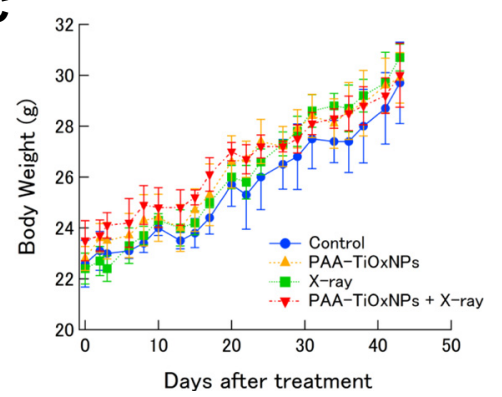

Fig. 4 Tumor growth-inhibitory effects of PAA-TiOxNPs combined with X-ray radiation. a Tumor appearance in the xenografts for each treatment after 43 days (arrowhead). b Changes in tumor size after each treatment. Each group consisted of 3 mice. Data are shown as the mean \pm SD. ${ }^{*} p<0.05$. c Body weight changes after each treatment

exogenous ROS-generating agents or compounds that inhibit the antioxidant system. Combinations of ROSgenerating agents with X-ray radiation, which is capable of abrogating cellular antioxidant systems, are likely to have an additive or synergistic cytotoxic effect. From our determination that the combination of X-ray irradiation and PAA-TiOxNPs induced higher amounts of ROS and DNA damage in vitro, it was at least speculated that the PAATiOxNPs might act as ROS-generating agents in response to X-ray irradiation in the cells. The mechanism might affect the combination effect observed in the colony forming assay (Fig. 3d).

It was noteworthy that the use of PAA-TiOxNPs in combination with X-ray radiation induced tumor growth inhibition in vivo. The effect of the combination therapy was significantly greater than that of each of the single treatments (Fig. 4a, b), thus indicating a potential synergistic effect. However, although our results indicate a potential role for the production of hydroxyl radicals from the PAA-TiOxNPs, the sites for ROS production (inside the cells, or on the outer membrane, or both) remain unclear. In the histochemical analyses, the PAA-TiOxNPs appeared to accumulate inside the cells (Fig. 5a), thus suggesting that the increase in ROS levels according to the Fenton reaction may occur inside the cells. Halliwell et al. previously reported that the hydroxyl radical could be produced via the Fenton reaction in the presence of biological free iron and superoxide, leading to oxidative damage [33]. In our experimental setting, a small radiation dose (5 Gy) was effective for induction of apoptosis and tumor shrinkage; larger doses or multiple doses will probably have greater effects. The use of the combination of PAA-TiOxNPs with X-ray radiation in vivo appeared to be effective for inhibiting tumor growth.

Metal nanoparticles have unique characteristics such as particle size, high surface-to-volume ratio, broad optical properties, and facile surface chemistry [34, 35]. Radiosensitization of gold nanoparticles (GNPs) occurs because of the high absorbance of gold and the resulting deposition of energy in surrounding tissues from photoelectrons and auger electrons, and because of the generation of ROS [36-39]. Compared to these findings for GNPs, fewer data appear to be available for the applications of TiOxNPs, and multiple aspects of TiOxNPs still need to be evaluated. Although our results indicate that TiOxNPs have potential for use as agents that enhance the effects of radiation, further research on this property of TiOxNPs in comparison to GNPs is necessary.

Our study has a few limitations. The route of administration was intra-tumoral injection, and the effects of intravenous injection were not tested. There are several reports indicating that intravenously injected GNPs can readily extravasate into advanced brain tumors, leading to increased survival of mice with advanced glioblastoma 


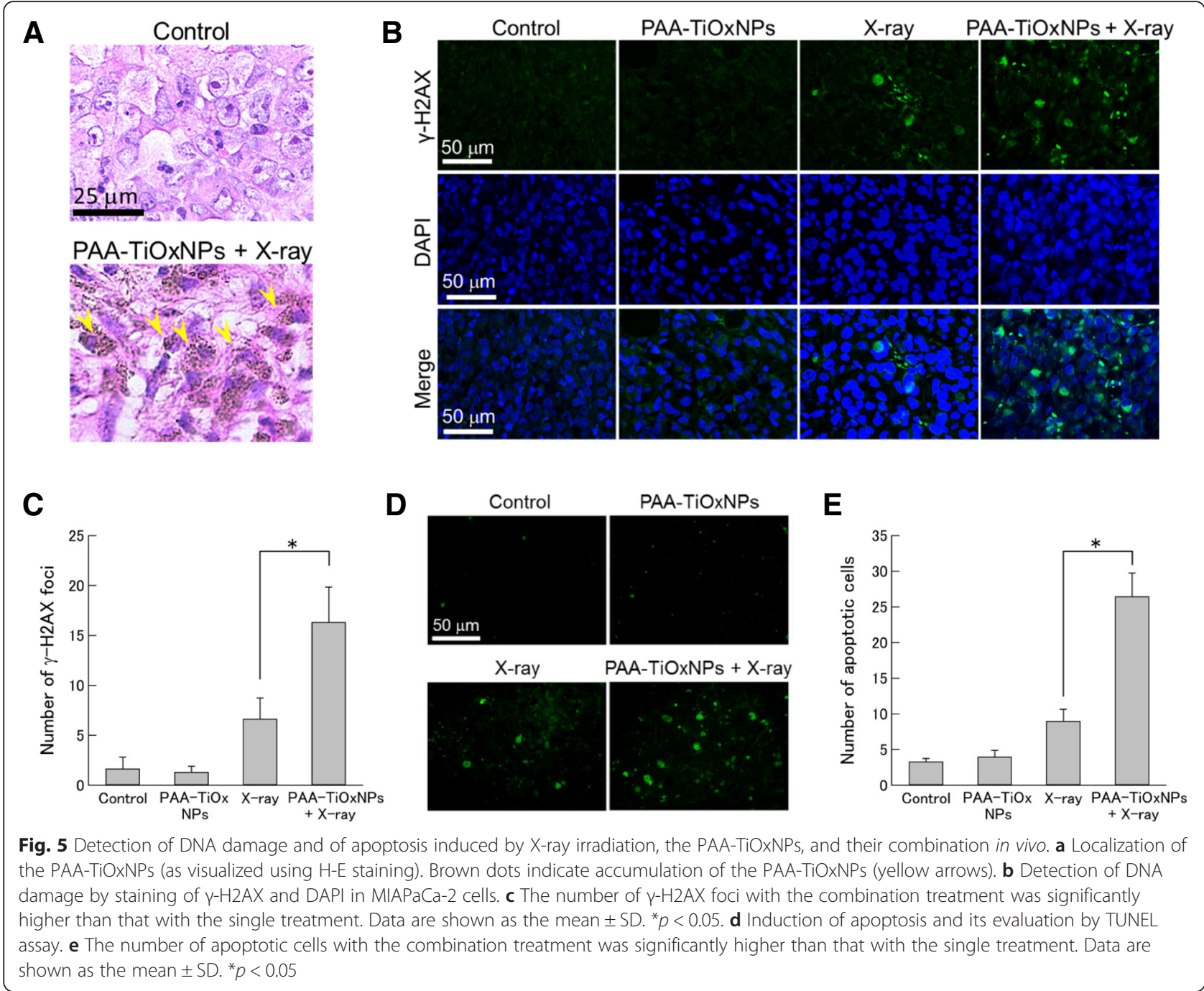

treated with radiotherapy plus GNPs $[40,41]$. Therefore, systemic intravenous administration of PAA-TiOxNPs may induce an additional effect. Further evaluation is warranted in this regard. On the contrary, some studies have reported protracted elimination of GNPs from the liver [42, 43], and other studies have reported the nephrotoxicity of GNPs $[44,45]$. Although no change in the weight of the mice was observed in our experimental setting, larger amounts of PAA-TiOxNPs seem to be necessary in case of systemic administration, and toxicity, including acute liver or renal toxicity, will need to be carefully evaluated.

\section{Conclusions}

In conclusion, $\mathrm{TiOxNPs}$ showed remarkable ROS production upon X-ray irradiation. PAA-TiOxNPs were effective in a mouse model using engrafted human pancreatic cancer cells. Although future studies will be required to confirm the therapeutic effects and potential toxicity of nanoparticles, our study shows that TiOxNPs are promising agents for enhancing the effects of radiation in pancreatic cancer therapy.

\section{Additional file}

Additional file 1: Details of the synthetic protocol for PAA-TiOxNPS formation from $\mathrm{TiO}_{2} \mathrm{NPs}$. (PPTX $151 \mathrm{~kb}$ )

\section{Abbreviations}

APF, 3'-(p-aminophenyl) fluorescein; $C_{-}-H_{2} D C F$, carboxy-2', 7'-dichlorofluorescein; DAPI, 4', 6-diaidino-2-phenylindole; DLS, dynamic light scattering; DNA, deoxyribonucleic acid; FACS, fluorescence activated cell sorting; GNPS, gold nanoparticles; $\mathrm{H}-\mathrm{E}$, hematoxylin and eosin; HE, hydroethidium; NPS, nanoparticles; PAA, polyacrylic acid; PBS, phosphate buffered saline; ROS, reactive oxygen species; $\mathrm{SD}$, standard deviation; $T E M$, transmission electron micrography; $\mathrm{TiO}_{2}$, titanium dioxide; $\mathrm{TiO}_{2} \mathrm{NPs}$, titanium dioxide nanoparticles; TiOxNPs, titanium peroxide nanoparticles; TUNEL, terminal deoxynucleotidyl transferase-mediated deoxyuridine triphosphate nick end labeling; UV, ultraviolet; XAFS, X-ray absorption fine structure: $Y-H 2 A X$, phosphorylated histone $2 A X$ 


\section{Acknowledgment}

The authors thank Izumi Takayama (Division of Radiation Oncology, Kobe University) for assistance with in vitro and in vivo studies.

\section{Funding}

This work was supported by a Health Labor Sciences Research Grant of the Ministry of Health, Labor and Welfare of the Japanese government (AK), and Grant-in-Aid (No.25670535 to RS; No. 25420831 to CO) for Exploratory Research from the Ministry of Education, Culture, Sports, Science and Technology.

\section{Availability of data and materials}

The datasets supporting the conclusions of this article are included within the article and its Additional file 1.

\section{Authors' contributions}

$\mathrm{CO}, \mathrm{RS}$, and AK contributed to the study design and concept. MN, KM, ZT, and $\mathrm{HA}$ performed practical work and acquired the data. $\mathrm{MN}, \mathrm{CO}, \mathrm{KS}, \mathrm{YN}$, and $\mathrm{CN}$ participated in the analysis and interpretation of the data. TT, MU, $\mathrm{SO}, \mathrm{KS}$, and ST contributed to administrative, technical, and material support. $\mathrm{MN}$ and RS contributed to manuscript writing. All of the authors read and approved the final manuscript.

\section{Competing interests}

The authors declare that they have no competing interests.

\section{Consent for publication}

Not applicable.

\section{Ethics approval and consent to participate}

All animal experiments in this study were approved by the Institutional Animal Care and Use Committee (Permission number: 100605R1) and performed according to Kobe University Animal Experimentation Regulations.

\section{Author details}

'Division of Radiation Oncology, Kobe University Graduate School of Medicine, 7-5-2 Kusunokicho, Chuouku, Kobe, Hyogo 650-0017, Japan. ${ }^{2}$ Department of Chemical Science and Engineering, Graduate School of Engineering, Kobe University, 1-1 Rokkoudaicho, Nadaku, Kobe, Hyogo 657-8501, Japan. ${ }^{3}$ Department of Biomolecular Engineering, Graduate School of Engineering, Tohoku University, 6-6 Aramaki, Aza, Aobaku, Sendai, Miyagi 980-8579, Japan. ${ }^{4}$ Joining and Welding Research Institute, Osaka University, 11-1 Mihogaoka, Ibaraki, Osaka 567-0047, Japan. ${ }^{5}$ Division of Environmental Engineering Science, Graduate School of Science and Technology, Gunma University, 1-5-1 Tenjincho, Kiryu, Gunma 376-8515, Japan. ${ }^{6}$ Graduate School of Science, Chiba University, 1-33 Yayoi, Inage, Chiba 263-8522, Japan. ${ }^{7}$ Institute of Multidisciplinary Research for Advanced Materials, Tohoku University, 2-1-1 Katahira, Aobaku, Sendai, Miyagi 980-8577, Japan.

\section{Received: 3 December 2015 Accepted: 2 July 2016}

\section{Published online: 07 July 2016}

\section{References}

1. Siegel RL, Miller KD, Jemal A. Cancer statistics, 2015. CA Cancer J Clin. 2015;65:5-29.

2. Sharma C, Eltawil KM, Renfrew PD, Walsh MJ, Molinari M. Advances in diagnosis, treatment and palliation of pancreatic carcinoma: 1990-2010. World J Gastroenterol. 2011;17:867-97.

3. Goodman KA, Hajj C. Role of radiation therapy in the management of pancreatic cancer. J Surg Oncol. 2013;107:86-96.

4. Yezhelyev MV, Gao X, Xing Y, Al-Hajj A, Nie S, O'Regan RM. Emerging use of nanoparticles in diagnosis and treatment of breast cancer. Lancet Oncol. 2006;7:657-67.

5. Kim BY, Rutka JT, Chan WC. Nanomedicine. N Engl J Med. 2010;363:2434-43.

6. Service RF. Materials and biology: Nanotechnology takes aim at cancer. Science. 2005;310:1132-4.

7. Wang AZ, Tepper JE. Nanotechnology in radiation oncology. J Clin Oncol. 2014;32(26):2879-85.
8. Baan R, Straif K, Grosse Y, Secretan B, El Ghissassi F, Cogliano V, et al. Carcinogenicity of carbon black, titanium dioxide, and talc. Lancet Oncol. 2006;7:295-6.

9. Lomer MC, Thompson RP, Powell JJ. Fine and ultrafine particles of the diet: influence on the mucosal immune response and association with Crohn's disease. Proc Nutr Soc. 2002;61:123-30.

10. Kakinoki K, Yamane K, Teraoka R, Otsuka M, Matsuda Y. Effect of relative humidity on the photocatalytic activity of titanium dioxide and photostability of famotidine. J Pharm Sci. 2004;93:582-9.

11. Sayes CM, Wahi R, Kurian PA, Liu Y, West JL, Ausman KD, et al. Correlating nanoscale titania structure with toxicity: a cytotoxicity and inflammatory response study with human dermal fibroblasts and human lung epithelial cells. Toxicol Sci. 2006:92:174-85.

12. Trouiller B, Reliene R, Westbrook A, Solaimani P, Schiestl RH. Titanium dioxide nanoparticles induce DNA damage and genetic instability in vivo in mice. Cancer Res. 2009;69:8784-9.

13. Reeves JF, Davies SJ, Dodd NJ, Jha AN. Hydroxyl radicals $(\bullet \mathrm{OH})$ are associated with titanium dioxide $\left(\mathrm{TiO}_{2}\right)$ nanoparticle-induced cytotoxicity and oxidative DNA damage in fish cells. Mutat Res. 2008;640:113-22.

14. Xu J, Sun Y, Huang J, Chen C, Liu G, Jiang Y, et al. Photokilling cancer cells using highly cell-specific antibody- $\mathrm{TiO}_{2}$ bioconjugates and electroporation. Bioelectrochemistry. 2007;71:217-22.

15. Ogino C, Shibata N, Sasai R, Takaki K, Miyachi Y, Kuroda S, et al. Construction of protein-modified $\mathrm{TiO}_{2}$ nanoparticles for use with ultrasound irradiation in a novel cell injuring method. Bioorg Med Chem Lett. 2010;20:5320-5.

16. Fujishima A, Rao TN, Tryk DA. Titanium dioxide photocatalysis. Photochem Rev. 2000;1:1-21.

17. Cai R, Kubota Y, Shuin T, Sakai H, Hashimoto K, Fujishima A. Induction of cytotoxicity by photoexcited $\mathrm{TiO}_{2}$ particles. Cancer Res. 1992;52:2346-8.

18. Blake DM, Maness P-C, Huang Z, Wolfrum EJ, Huang J. Application of the photocatalytic chemistry of titanium dioxide to disinfection and the killing of cancer cells. Sep Purif Methods. 1999:28:1-50.

19. Retif $P$, Pinel $S$, Toussaint M, Frochot $C$, Chouikrat R, Bastogne $T$, et al. Nanoparticles for radiation therapy enhancement: the key parameters. Theranostics. 2015;5(9):1030-44.

20. Wang J, Fan Y. Lung injury induced by $\mathrm{TiO}_{2}$ nanoparticles depends on their structural features: size, shape, crystal phases, and surface coating. Int J Mol Sci. 2014:15(12):22258-78.

21. Boonstra $\mathrm{AH}$, Mutsaers CAHA. Adsorption of hydrogen peroxide on the surface of titanium dioxide. J Phys Chem. 1975;79:1940-3.

22. Quinn RC, Zent AP. Peroxide-modified titanium dioxide: a chemical analog of putative Martian soil oxidants. Orig Life Evol Biosph. 1999;29:59-72.

23. Sánche LD, Taxt-Lamolle SF, Hole EO, Krivokapićb A, Sagstuenb E, Haugen $\mathrm{HJ}$. $\mathrm{TiO}_{2}$ suspension exposed to $\mathrm{H}_{2} \mathrm{O}_{2}$ in ambient light or darkness: Degradation of methylene blue and EPR evidence for radical oxygen species. Appl Catal B Environ. 2013;142-143:662-7.

24. Kanehira K, Banzai T, Ogino C, Shimizu N, Kubota Y, Sonezaki S. Properties of $\mathrm{TiO}_{2}$-polyacrylic acid dispersions with potential for molecular recognition. Colloids Surf. 2008:B64:10-5.

25. Srivastava SK, Yamada R, Ogino C, Kondo A. Biogenic synthesis and characterization of gold nanoparticles by Escherichia coli K12 and its heterogeneous catalysis in degradation of 4-nitrophenol. Nanoscale Res Lett. 2013;8(1):70.

26. Setsukinai K, Urano Y, Kakinuma K, Majima HJ, Nagano T. Development of novel fluorescence probes that can reliably detect reactive oxygen species and distinguish specific species. J Biol Chem. 2003;278:3170-5.

27. Sasaki R, Suzuki $Y$, Yonezawa $Y$, Ota $Y$, Okamoto $Y$, Demizu $Y$. DNA polymerase gamma inhibition by vitamin K3 induces mitochondriamediated cytotoxicity in human cancer cells. Cancer Sci. 2008;99(5):1040-8.

28. Bonner WM, Redoc CE, Dickey JS, Nakamura AJ, Sedelnikova OA, Solier S, et al. $y$ H2AX and cancer. Nat Rev Cancer. 2008;8:957-67.

29. Mukubou H, Tsujimura T, Sasaki R, Ku Y. The role of autophagy in the treatment of pancreatic cancer with gemcitabine and ionizing radiation. Int J Oncol. 2010;37(4):821-8.

30. Zhang XD, Wu D, Shen X, Chen J, Sun YM, Liu PX, et al. Size-dependent radiosensitization of $\mathrm{PEG}$-coated gold nanoparticles for cancer radiation therapy. Biomaterials. 2012;33:6408-19.

31. Sasaki R, Shirakawa T, Zhang ZJ, Tamekane A, Matsumoto A, Sugimura K, et al. Additional gene therapy with Ad5CMV-p53 enhanced the efficacy of radiotherapy in human prostate cancer cells. Int J Radiat Oncol Biol Phys. 2001;51(5):1336-45. 
32. Trachootham D, Alexandre J, Huang P. Targeting cancer cells by ROSmediated mechanisms: a radical therapeutic approach? Nat Rev Drug Discov. 2009;8(7):579-91.

33. Halliwell B, Gutteridge JM. Biologically relevant metal ion dependent hydroxyl radical generation. An update FEBS Lett. 1992;307:108-12.

34. Su XY, Liu PD, Wu H, Gu N. Enhancement of radiosensitization by metal-based nanoparticles in cancer radiation therapy. Cancer Biol Med. 2014;11(2):86-91.

35. Conde J, Doria G, Baptista P. Noble metal nanoparticles applications in cancer. J Drug Deliv. 2012;2012:751075.

36. Al Zaki A, Joh D, Cheng Z, De Barros AL, Kao G, Dorsey J, et al. Gold-loaded polymeric micelles for computed tomography-guided radiation therapy treatment and radiosensitization. ACS Nano. 2014;8(1):104-12.

37. Misawa M, Takahashi J. Generation of reactive oxygen species induced by gold nanoparticles under $x$-ray and UV Irradiations. Nanomedicine. 2011;7:604-14.

38. Geng F, Song K, Xing JZ, Yuan C, Yan S, Yang Q, et al. Thio-glucose bound gold nanoparticles enhance radio-cytotoxic targeting of ovarian cancer. Nanotechnology. 2011;22:285101.

39. Ngwa W, Kumar R, Sridhar S, Korideck H, Zygmanski P, Cormack RA, et al. Targeted radiotherapy with gold nanoparticles: current status and future perspectives. Nanomedicine (Lond). 2014;9(7):1063-82.

40. Hainfeld JF, Smilowitz HM, O'Connor MJ, Dilmanian FA, Slatkin DN. Gold nanoparticle imaging and radiotherapy of brain tumors in mice. Nanomedicine (Lond). 2013;8:1601-9.

41. Joh DY, Sun L, Stangl M, Al Zaki A, Murty S, Santoiemma PP, et al. Selective targeting of brain tumors with gold nanoparticle-induced radiosensitization. PLoS One. 2013;8(4), e62425.

42. Balasubramanian SK, Jittiwat J, Manikandan J, Ong CN, Yu LE, Ong WY Biodistribution of gold nanoparticles and gene expression changes in the liver and spleen after intravenous administration in rats. Biomaterials. 2010;31:2034-42.

43. Sadauskas E, Danscher G, Stoltenberg M, Vogel U, Larsen A, Wallin H. Protracted elimination of gold nanoparticles from mouse liver. Nanomedicine. 2009;5:162-9.

44. Hainfeld JF, Slatkin DN, Smilowitz HM. The use of gold nanoparticles to enhance radiotherapy in mice. Phys Med Biol. 2004;49:N309-15.

45. Chang MY, Shiau AL, Chen YH, Chang CJ, Chen HH, Wu CL. Increased apoptotic potential and dose-enhancing effect of gold nanoparticles in combination with single-dose clinical electron beams on tumor-bearing mice. Cancer Sci. 2008;99:1479-84.

\section{Submit your next manuscript to BioMed Central and we will help you at every step:}

- We accept pre-submission inquiries

- Our selector tool helps you to find the most relevant journal

- We provide round the clock customer support

- Convenient online submission

- Thorough peer review

- Inclusion in PubMed and all major indexing services

- Maximum visibility for your research

Submit your manuscript at www.biomedcentral.com/submit

C Biomed Central 